\title{
Vertical morphotropic phase boundary in lead-free piezoelectric ceramics $(\mathrm{K}, \mathrm{Na}, \mathrm{Li}) \mathrm{NbO}_{3}-\mathrm{BaZrO}_{3}-(\mathrm{La}, \mathrm{Na}) \mathrm{TiO}_{3}$ system
}

\author{
Ryosuke Baba, Tomoaki Karaki* and Tadashi Fujii \\ Department of Intelligent Systems Design Engineering, \\ Toyama Prefectural University, Imizu, Toyama 939-0398, Japan \\ *chen@pu-toyama.ac.jp
}

Received 11 December 2015; Revised 7 January 2016; Accepted 8 February 2016; Published 14 April 2016

\begin{abstract}
A morphotropic phase boundary (MPB) with temperature-independent behavior, the so-called vertical MPB was investigated in lead-free $(\mathrm{K}, \mathrm{Na}, \mathrm{Li}) \mathrm{NbO}_{3}-\mathrm{BaZrO}_{3}-(\mathrm{La}, \mathrm{Na}) \mathrm{TiO}_{3}$ ternary ceramic system. The specimens were synthesized by a conventional solidstate reaction method, and their crystal structures as well as their MPB were determined from X-ray diffraction patterns measured from room temperature to $300^{\circ} \mathrm{C}$. The vertical MPB composition was determined to be $0.9025\left(\mathrm{~K}_{0.45} \mathrm{Na}_{0.5} \mathrm{Li}_{0.05}\right) \mathrm{NbO}_{3}-$ $0.09 \mathrm{BaZrO}_{3}-0.0075(\mathrm{La}, \mathrm{Na}) \mathrm{TiO}_{3}$ and the Curie temperature was found to be about $195^{\circ} \mathrm{C}$. It was successfully confirmed that ceramic samples of this system could be sintered in a reducing atmosphere. For lead-free piezoceramic applications of multilayer actuators using $\mathrm{Ni}$ inner electrodes, the results obtained in this work have important practical implications.
\end{abstract}

Keywords: Lead-free piezoceramics; vertical morphotropic phase boundary; reducing atmosphere; high-temperature XRD; phase transition.

\section{Introduction}

Piezoelectric materials are widely used in modern electronic devices. Among them, lead-based piezoelectric ceramics, $\mathrm{Pb}$ $(\mathrm{Zr}, \mathrm{Ti}) \mathrm{O}_{3}$ (PZT) system ceramics, are widely used as actuators and transducers because of their excellent piezoelectric properties. The PZT system has a morphotropic phase boundary (MPB) between rhombohedral phase and tetragonal phase. It is well known that dielectric and piezoelectric properties show their maximum values around the MPB composition. ${ }^{1}$ Additionally, in composition-temperature phase diagram of the PZT the MPB is almost perpendicular to the composition axis, indicating that the PZT ceramics have a high performance in a wide temperature range with high stability. Therefore, the vertical MPB is very important for the piezoelectric applications.

Because of the harmful lead contained in the PZT, research and development of lead-free piezoelectric materials have attracted much attention. In particular, lead-free $\mathrm{BaTiO}_{3}$-based, $(\mathrm{Bi}, \mathrm{Na}) \mathrm{TiO}_{3}$-based, and $(\mathrm{K}, \mathrm{Na}) \mathrm{NbO}_{3}$-based piezoelectric ceramics have been considered as replacement candidates for the PZT ceramics. ${ }^{2-17}$ The $\mathrm{BaTiO}_{3}$-based, $(\mathrm{Bi}$, $\mathrm{Na}) \mathrm{TiO}_{3}$-based, and $(\mathrm{K}, \mathrm{Na}) \mathrm{NbO}_{3}$-based system ceramics have the same perovskite structure as the PZT, and the MPB compositions were also formed/discovered in those systems. In our early work, one of the lead-free piezoceramics with vertical MPB has been successfully developed by adjusting the MPB slope of $\left(\mathrm{K}_{0.45} \mathrm{Na}_{0.5} \mathrm{Li}_{0.05}\right) \mathrm{NbO}_{3}-\mathrm{BaZrO}_{3}(\mathrm{KNLN}-$ BZ) binary system using the rhombohedral $(\mathrm{Bi}, \mathrm{Na}) \mathrm{TiO}_{3}$ (BNT) as a third component. ${ }^{18}$
Recently, multilayer actuators were required for engineinjector applications. To reduce the total cost, Ni inner electrode was selected. In this case, the $\mathrm{Ni}$ electrode and the ceramics have to be co-sintered in a reducing atmosphere to prevent oxidation of the Ni. ${ }^{19-22}$ However, the vertical MPB composition developed in our early work, lead-free KNLNBZ-BNT, contains very small amount of $\mathrm{Bi}$. The $\mathrm{Bi}_{2} \mathrm{O}_{3}$ was metalized and evaporated during the sintering process in the reducing atmosphere. Chean et al. reported that Bi in BNT could be replaced by small amount of $\mathrm{La}$ and a single perovskite structure was kept. ${ }^{23}$ The La has the same ionic valence and almost same ionic radius as Bi. Furthermore, the $\mathrm{La}_{2} \mathrm{O}_{3}$ can be sintered in reducing atmosphere without metallization nor evaporation. In this study, the MPB formation and the slope of KNLN-BZ binary system adjusted by (La, $\mathrm{Na}) \mathrm{TiO}_{3}(\mathrm{LNT})$ were investigated.

\section{Experimental Procedure}

$(1-x-y) \mathrm{KNLN}-x \mathrm{BZ}-y \mathrm{LNT}(0.07 \leq x \leq 0.1)(y=0.0075$, $0.01)$ ternary system ceramics with compositions denoted by numbers 1-10, as shown in Fig. 1, were prepared by a conventional solid-state synthesis method. Carbonate and oxide powders of $\mathrm{K}_{2} \mathrm{CO}_{3}, \mathrm{Na}_{2} \mathrm{CO}_{3}, \mathrm{Li}_{2} \mathrm{CO}_{3}, \mathrm{BaCO}_{3}, \mathrm{La}_{2} \mathrm{O}_{3}, \mathrm{TiO}_{2}$, $\mathrm{ZrO}_{2}$, and $\mathrm{Nb}_{2} \mathrm{O}_{5}$ were used as raw materials. Stoichiometrically weighed powders were mixed by planetary ball milling with zirconia balls and ethanol for $4 \mathrm{~h}$. After drying, the mixtures were calcined at $1000^{\circ} \mathrm{C}$ in air for $2 \mathrm{~h}$, and then the powders were crushed and ball-milled again for $15 \mathrm{~h}$. The

This is an Open Access article published by World Scientific Publishing Company. It is distributed under the terms of the Creative Commons Attribution 4.0 (CC-BY) License. Further distribution of this work is permitted, provided the original work is properly cited. 


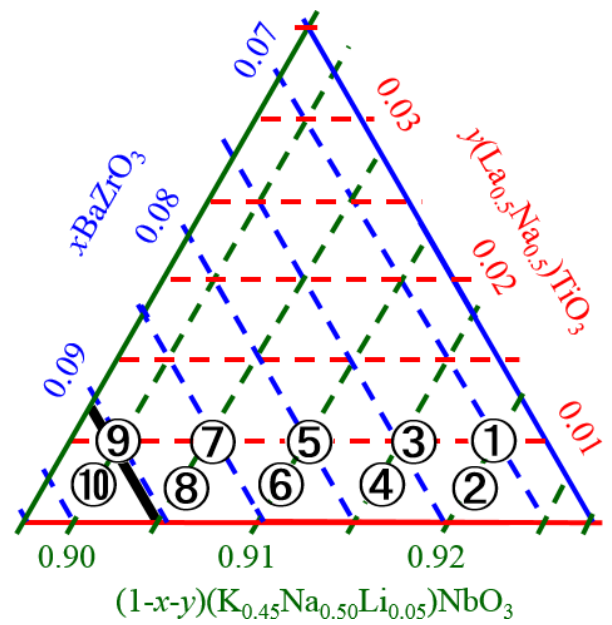

Fig. 1. (Color online) Ternary ceramic compositions investigated in this work.

final ceramic powders with submicron size particles were mixed with a polyvinyl alcohol binder and then formed into pellets by pressing at $170 \mathrm{MPa}$. After burning out the binder, the pellets were sintered at $1190^{\circ} \mathrm{C}$ for $5 \mathrm{~h}$. The sintered specimens were lapped to $1 \mathrm{~mm}$ thickness and then silverelectroded on both surfaces at $650^{\circ} \mathrm{C}$ for $2 \mathrm{~h}$. The bulk ceramics were poled with an electric field of $4.0 \mathrm{kV} / \mathrm{mm}$ in silicone oil at $150^{\circ} \mathrm{C}$ for $15 \mathrm{~min}$.

Powder X-ray diffraction (XRD) analysis was carried out using $\mathrm{Cu} \mathrm{K} \alpha$ radiation. Specimens of sintered powders were measured by XRD analysis in the range $2 \theta=20-60^{\circ}$ at room temperature (RT) to confirm their perovskite structure. The pseudocubic perovskite indication was used in our work. The (200) pc reflections of selected specimens were measured by XRD analysis from RT to $300^{\circ} \mathrm{C}$ for phase transition determination. For perovskite structure materials, weak-left and strong-right double $(200)_{\mathrm{pc}}$ reflections indicate the tetragonal phase, strong-left and weak-right double $(200)_{\mathrm{pc}}$ reflection indicates the orthorhombic phase, and a single $(200)_{\mathrm{pc}}$ reflection indicates the rhombohedral or cubic phase. ${ }^{18}$ The Curie temperature $T_{\mathrm{C}}$ was determined at the peak value from the curve of the temperature dependence of the dielectric constant at $1 \mathrm{kHz}$. Electromechanical coupling factor $k_{\mathrm{p}}$ was measured by the resonance-antiresonance method using a Poisson's ratio of 0.3 .

\section{Results and Discussion}

Figure 2(a) shows XRD patterns of numbers 1-10 specimens at RT. The XRD patterns shows that all the samples had single perovskite phase. The $(200)_{\text {pc }}$ reflection peaks located at $2 \theta=44.5-46^{\circ}$ are magnified in Fig. 2(b). It could be clearly seen that numbers 1 and 2 specimens had weak-left and strong-right double $(200)_{\mathrm{pc}}$ reflections indicating tetragonal phase and number 10 specimen had a rhombohedral phase. However, numbers 3-9 specimens had nonbisymmetry

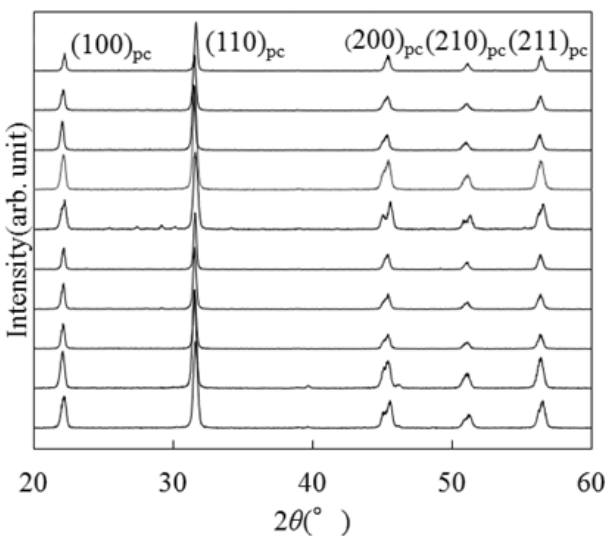

(a)

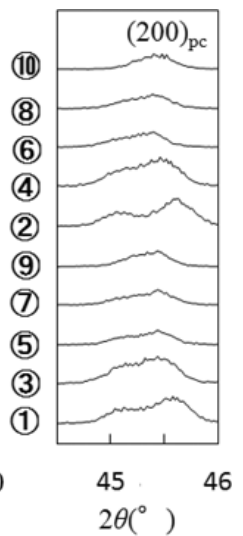

(b)
Fig. 2. XRD patterns of numbers $1-10$ specimens at RT (a) from $2 \theta=20^{\circ}$ to $60^{\circ}$ and (b) $(200)_{\mathrm{pc}}$ refrection.

single reflections. After peak-separating and peak-fitting treatment, it was determined that numbers 3-9 specimens had a tetragonal phase. From the above, MPB in this ternary system at RT could be determined between numbers 8 and 10, as the solid line shown in Fig. 1.

High-temperature XRD patterns of numbers 1,4 , and 7, 8 and 10 specimens at $2 \theta=44.5-46^{\circ}$ and their fitted peaks are shown in Figs. 3(a)-3(e). The double (200) $)_{\mathrm{pc}}$ reflection changed to single $(200)_{\mathrm{pc}}$ reflection at $200^{\circ} \mathrm{C}$ for number 7 , and at $250^{\circ} \mathrm{C}$ for numbers 1 and 4 specimens, respectively. The Curie temperatures of all the specimens were determined at the peak value from the curve of temperature dependence of dielectric constant at $1 \mathrm{kHz}$. Some of them, curves of numbers 1 and 7 specimens are shown in Fig. 4. The $T_{\mathrm{C}}$ of numbers 1 and 7 specimens were $235^{\circ} \mathrm{C}$ and $205^{\circ} \mathrm{C}$, which agreed with the results observed in Figs. 3(a) and 3(c). At line of $y=$ 0.0075 (Fig. 1), the $T_{\mathrm{C}}$ decreased at $20^{\circ} \mathrm{C} / \mathrm{mol} \%$ with increase of BZ. The $T_{\mathrm{C}}$ of specimens at $y=0.0075$ line were little higher than that at $y=0.01$ line. Near the MPB composition, the $T_{\mathrm{C}}$ of numbers 8,9 and 10 specimens were determined as around $202^{\circ} \mathrm{C}, 195^{\circ} \mathrm{C}$ and $190^{\circ} \mathrm{C}$, respectively. The $T_{\mathrm{C}}$ of this ternary system is lower than that BNT one of KNLN-BZ-BNT system. ${ }^{18}$ Considering the $T_{\mathrm{C}}$ determined from the dielectric constant curve and the XRD date in Fig. 3(b), lattice constant change of number 4 specimen was obtained, as plotted in Fig. 5.

To investigate the slope of the MPB, numbers 8 and 10 specimens were also analyzed by the high-temperature XRD. Figures 3(d) and 3(e) show the high-temperature XRD measurement results. It could be clearly seen that the number 10 specimen had a rhombohedral phases from RT to the $T_{\mathrm{C}}$, and then the perovskite phase changed to cubic phase. Number 8 specimen had tetragonal phases from RT to the $T_{\mathrm{C}}$, and had a cubic phase above the $T_{\mathrm{C}}$. Considering the composition difference between the two specimens, we could suggest an almost vertical MPB existing near the composition of $0.9025 \mathrm{KNLN}-0.09 \mathrm{BZ}-0.0075 \mathrm{LNT}$ with the $T_{\mathrm{C}}$ of about 


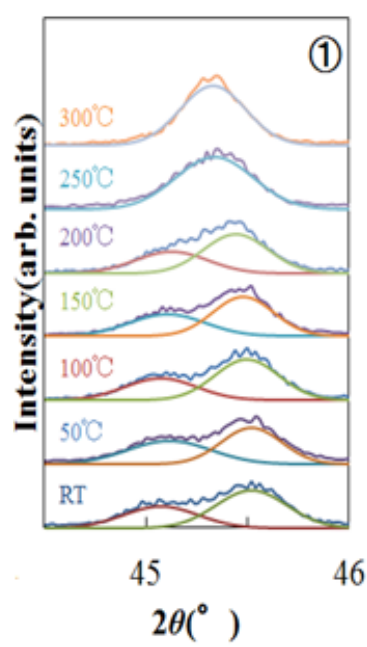

(a)

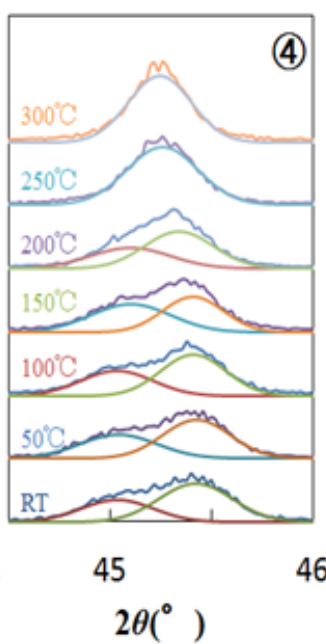

(b)

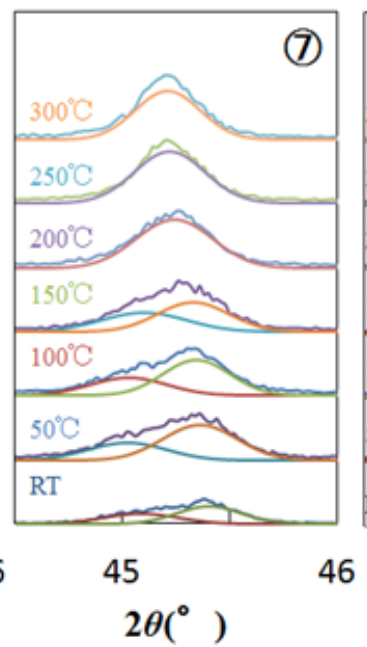

(c)

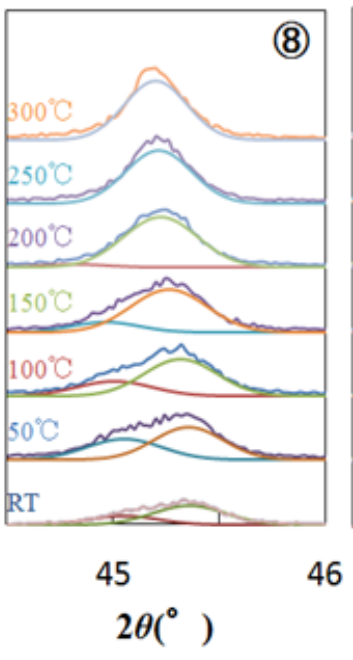

(d)

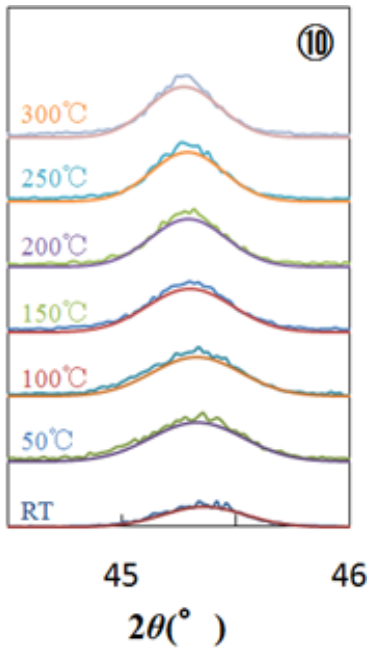

(e)

Fig. 3. (Color online) High-temperature XRD patterns of (200) $)_{\mathrm{pc}}$ reflections and fitted peaks of (a) number 1, (b) number 4, (c) number 7, (d) number 8 and (e) number 10 specimens.

$195^{\circ} \mathrm{C}$. Electromechanical coupling factor $k_{\mathrm{p}}$ of a polled number 8 specimen was measured from RT to $210^{\circ} \mathrm{C}$. As a result, $k_{\mathrm{p}}=40 \%$ at $\mathrm{RT}$ and $k_{\mathrm{p}}=6 \%$ at $200^{\circ} \mathrm{C}$ were obtained.

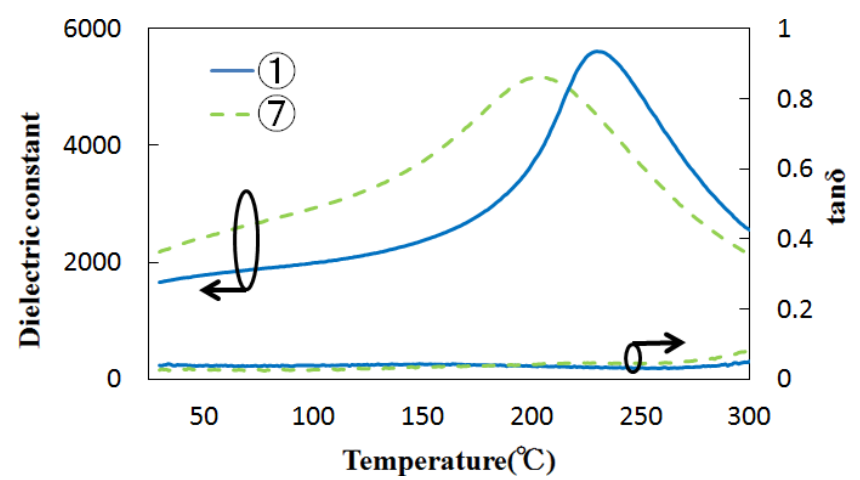

Fig. 4. Temperature dependence of dielectric constant of numbers 1 and 7 specimens.

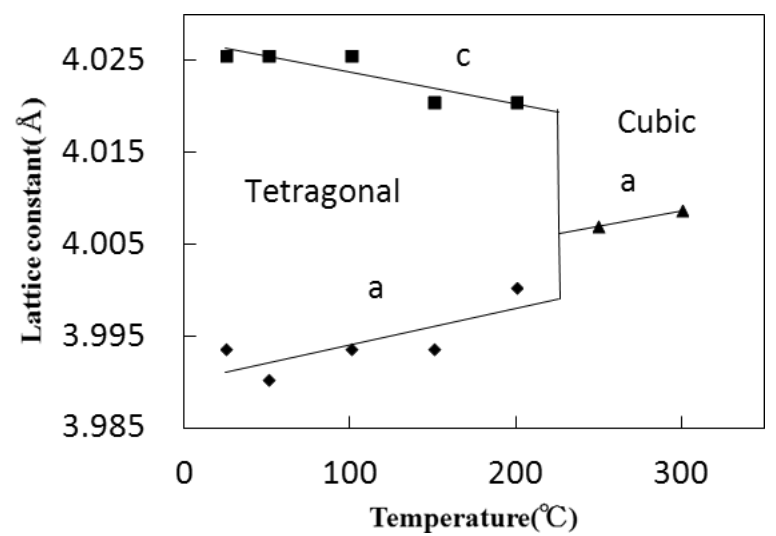

Fig. 5. Temperature dependence of lattice constants of number 4 specimen.
Therefore, it was confirmed that number 8 specimen had the piezoelectricity until the $T_{\mathrm{C}}$ and there was no phase transition from RT to the $T_{\mathrm{C}}$. Figure 6 shows the phase diagram of $(1-x-y) \mathrm{KNLN}-x \mathrm{BZ}-y \mathrm{LNT}(y=0.0075)$ ceramic system nearby the vertical MPB. The $k_{\mathrm{p}}$ values of number 8 specimen, however, were smaller than those expected. It was considered that the specimen had not been well prepared and manufacturing process needed an improvement. Further investigation of the above lead-free piezoceramics with good performance in terms of piezoelectric properties is in progress.

One of number 8 specimens was tested to be sintered in reducing atmosphere. $\mathrm{N}_{2}-2 \% \mathrm{H}_{2}$ gas was used and the oxygen partial pressure was about $1 \times 10^{-6} \mathrm{~Pa}$. After sintered in the reducing atmosphere at $1190^{\circ} \mathrm{C}$ for $4 \mathrm{~h}$, the specimen was thermal-treated in air at $1000^{\circ} \mathrm{C}$ for $3 \mathrm{~h}$. This specimen had

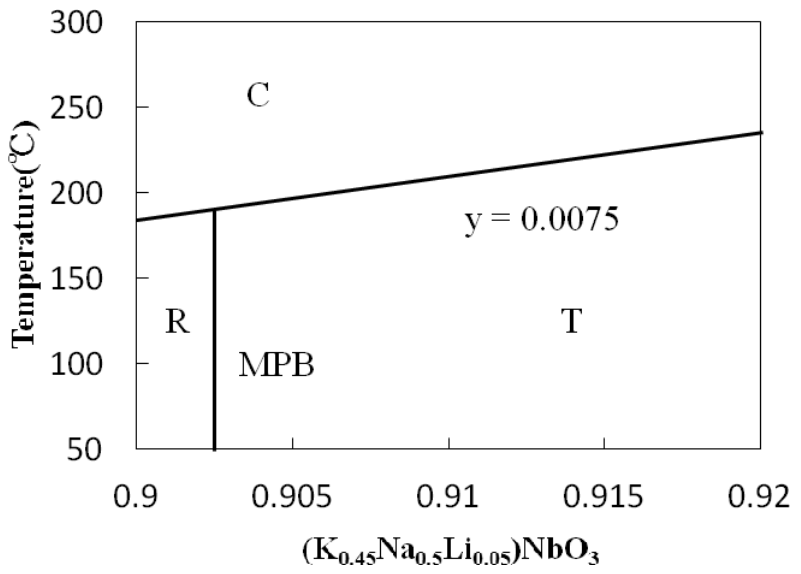

Fig. 6. Phase diagram of $(1-x-y)$ KNLN-xBZ-yLNT $\quad(y=$ $0.0075)$ ceramics nearby MPB. 
high density ( $>97 \%$ ) and $d_{33}$ about $270 \mathrm{pC} / \mathrm{N}$ at RT (measured by a $d_{33}$ meter).

\section{Conclusions}

In KNLN-BZ-LNT ternary ceramic system, there is a temperature-independent MPB, the so-called vertical MPB located around composition of $0.9025 \mathrm{KNLN}-0.09 \mathrm{BZ}-$ $0.0075 \mathrm{LNT}$ with a $T_{\mathrm{C}}$ of about $195^{\circ} \mathrm{C}$. The piezoelectric properties were confirmed from RT to the $T_{\mathrm{C}}$, indicating that there is no phase transition in the temperature range. Compared with the KNLN-BZ-BNT system reported by our group, there is no $\mathrm{Bi}$ element in the component, so that the ceramic sample was successfully sintered in a reducing atmosphere. For lead-free piezoceramic applications of multilayer actuators using $\mathrm{Ni}$ inner electrodes, such as engineinjector, the results obtained in this work have important practical implications.

\section{Acknowledgment}

This work was partly supported by the CAS/SAFEA International Partnership Program for Creative Research Teams.

\section{References}

${ }^{1}$ B. Jaffe, W. R. Cook and H. Jaffe, Piezoelectric Ceramics (Academic Press, New York, 1971).

${ }^{2}$ T. Karaki, K. Yan, T. Miyamoto and M. Adachi, Jpn. J. Appl. Phys. 46, L97 (2007).

${ }^{3}$ T. Karaki, K. Yan and M. Adachi, Jpn. J. Appl. Phys. 46, 7035 (2007).

${ }^{4}$ T. Karaki, K. Yan and M. Adachi, Appl. Phys. Express 1, 111402 (2008).
${ }^{5}$ I. Fujii, R. Mitsui, K. Nakashima, N. Kumada, M. Shimada, T. Watanabe, J. Hayashi, H. Yabuta, M. Kubota, T. Fukui and S. Wada, Jpn. J. Appl. Phys. 50, 09ND07 (2011).

${ }^{6}$ K. Yan, K. Matsumoto, T. Karaki and M. Adachi, J. Am. Ceram. Soc. 93, 3823 (2010).

${ }^{7}$ D. Maurya, A. Pramanick, K. An and S. Priya, Appl. Phys. Lett. 100, 172906 (2012).

${ }^{8}$ Y. Sakai and T. Futakuchi, Jpn. J. Appl. Phys. 52, 09KA12 (2013).

${ }^{9}$ H. Nagata, M. Yoshida, Y. Makiuchi and T. Takenaka, Jpn. J. Appl. Phys. 42, 7401 (2003).

${ }^{10}$ Y. Hiruma, H. Nagata and T. Takenaka, Jpn. J. Appl. Phys. 45, 7409 (2006).

${ }^{11}$ D. Xiao, J. Adv. Dielect. 1, 33 (2011).

${ }^{12}$ Y. Saito, H. Takao, T. Tani, T. Nonoyama, K. Takatori, T. Homma, T. Nagaya and M. Nakamura, Nature 432, 84 (2004).

${ }^{13}$ R. Zuo, X. Fang and C. Ye, Appl. Phys. Lett. 90, 092904 (2007).

${ }^{14}$ K. Kusumoto, Jpn. J. Appl. Phys. 45, 7440 (2006).

${ }^{15}$ B. Zhang, J. Wu, X. Cheng, X. Wang, D. Xiao, J. Zhu, X. Wang and X. Lou, ACS Appl. Mater. Interface 6, 7718 (2013).

${ }^{16}$ Y. Sakai, T. Futakuchi, T. Karaki and M. Adachi, Jpn. J. Appl. Phys. 53, 09PB07 (2014).

${ }^{17}$ F. Chen, Y.-H. Li, G.-Y. Gao, F.-Z. Yao, K. Wang, J.-F. Li, X.-L. Li, X.-Y, Gao and W. Wu, J. Am. Ceram. Soc. 98, 1372 (2015).

${ }^{18}$ T. Karaki, T. Katayama, K. Yoshida, S. Maruyama and M. Adachi, Jpn. J. Appl. Phys. 52, 09KD11 (2013).

${ }^{19}$ H. Miimi, K. Mihara, Y. Sakabe and M. Kuwabara, Jpn. J. Appl. Phys. 46, 6715 (2007).

${ }^{20}$ S. Kawada, M. Kimura, Y. Higuchi and H. Takagi, Appl. Phys. Express 2, 111401 (2009).

${ }^{21}$ H. Hayashi, S. Kawada, M. Kimura, Y. Nakai, T. Tabata, K. Shiratsuyu, K. Nada and H. Takagi, Jpn. J. Appl. Phys. 51, 09LD01 (2012).

${ }^{22}$ H. Ishii, S. Kawada, S. Suzuki, A. Honda, S. Higai, H. Hayashi, T. Okazawa, M. Kimura, S. Omiya, N. Kubodera and T. Konoike, Jpn. J. Appl. Phys. 52, 09KD06 (2013).

${ }^{23}$ M. L. Chean, K. A. Razak and C. Y. Ng, Adv. Mater. Res. 858, 141 (2014). 